Dr Helen Warner

Lecturer in Cultural Politics, Communication and Media Studies

School of Politics, Philosophy Language and Communication Studies

University of East Anglia

Email: helen.warner@uea.ac.uk Tel: 01603597485

Biography: Dr Helen Warner is a lecturer in Cultural Politics, Communications and Media Studies at the University of East Anglia. Her research interests include gender, production culture, fashion, costume, and celebrity culture. She is the author of Fashion on TV (2013) and editor of The Politics of Being a Woman (2014 with Dr Heather Savigny).

\begin{abstract}
In April 2013 the Department of Culture, Media and Sport announced plans to remove 'craft' from the list of recognised creative industries, initially claiming that craft occupations are 'often concerned with the manufacturing process, rather than the creative process' (DCMS, 2013). ${ }^{1}$ Concerns were immediately raised within the craft sector that such changes would cause a shift in the symbolic meaning of craft that would in turn, devalue the industry and render its workers invisible (Bennett, 2013). Yet precisely at the moment in which visibility was thought to be at risk, the craft sector was experiencing global hypervisibility within mainstream and online media spaces. This article examines the precise nature of this media visibility at a time of political uncertainty and contends that an investigation into the symbolic meaning of craft cannot overlook the importance of representational culture. Consequently, media studies offers a unique lens through which to examine the politics of craft and contribute meaningful responses to the following questions: how is the meaning of craft articulated in the symbolic environment at a time of political contestation? What is the role of gender in the mediated representation of craftwork? These questions inform the analysis of a specific example of representational culture: Kirstie's Crafty Christmas. This one off episode documents Allsopp's attempts to source handmade gifts and decorations from UK craft workers and enables the concerns above to be raised within a very specific context: the Christmas festival. Both craft and festive rituals blur boundaries between work/leisure and public/private in similar ways; which in the case of craft becomes problematic for policy makers. In the case of Kirstie's Crafty Christmas, this blurring of boundaries promotes problematic (gendered) hierarchies that position the work of micro-entrepreneurs as necessary, domestic unpaid labour and in so doing, privatize and deskill women's home-based creative work.
\end{abstract}

\footnotetext{
${ }^{1}$ The sentence was changed in later documents. See https://www.gov.uk/government/uploads/system/uploads/attachment data/file/203296/Classifying and Measuring the Creative Industries Consultation Paper April 2013-final.pdf
} 


\section{Creativity, Craft and Christmas: Textual negotiations and the politics of Kirstie's Crafty Christmas}

\section{Keywords: Craft, Gender, Micro-entrepreneurs, Domesticity, Representational Culture}

In April 2013 the Department of Culture, Media and Sport announced plans to remove 'craft' from the list of recognized creative industries, initially claiming that craft occupations were 'often concerned with the manufacturing process, rather than the creative process'. ${ }^{i}$ While the DCMS was eager to clarify that the proposed change was designed to ensure a more systematic and robust way of recording economic activity within the UK, the plans were met with strong opposition from those working in the sector. Concerns were immediately raised by practitioners and campaigners alike, that the failure to recognize craft as a creative enterprise would engender a shift in symbolic value. Writing for the Guardian in May 2013, Julia Bennett (research and policy manager for the Crafts Council) argued that removing craft from the creative industries would make it virtually impossible to account for the sector's contribution to the economy (estimated at $£ 3.4 \mathrm{bn}$ ) ${ }^{\mathrm{ii}}$ and render its workers invisible.

The proposal from government prompted a comprehensive report from the UK Craft Council in which the DCMS were criticized for significantly 'under-estimat[ing] the scale of the full craft industry',iii and for failing to properly account for the contribution of micro-businesses to the UK economy. The craft council challenged the government's methodology for defining and measuring the craft industry and proposed new ways for government to measure the contribution of microentrepreneurs. While the DCMS ultimately scrapped plans to remove craft from the list of creative industries, as of 2015 the data sources used by government continue to discount the work of micro-entrepreneurs. This lack of recognition continues to have significant implications for the future of these micro-businesses (as it affects the allocation of funding etc), and stands to disproportionately disadvantage women, who in the post-2008 climate, make up the majority of micro-entrepreneurs in the craft sector (Luckman 2015).

Precisely at the moment in which representation at the level of policy was thought to be at risk, the craft sector was experiencing global hypervisibility within mainstream and online media spaces. In addition to popular social networking sites, Twitter, Facebook and Instagram, micro-entrepreneurs found unprecedented publicity and entrepreneurial opportunity on scrapbooking site Pinterest and online marketplaces, Etsy and Big Cartel. In July 2013 Pinterest was reportedly valued at $\$ 2.5 \mathrm{bn}$ and was approaching 50 million users, while in the same year, Etsy registered global sales of $\$ 94.7$ million. ${ }^{i v}$ This exposure was not only relegated to online spaces; broadcast television also provided craft with a public forum; based on the success of The Great British Bake Off (2010- ), Love Productions launched The Great British Sewing Bee airing in February 2013 on BBC2, while Channel 4 capitalized on the popularity of media personality and craft enthusiast Kirstie Allsopp by introducing Kirstie's Handmade Treasures (January 2013) and Kirstie's Vintage Gems (February 2013). 
As the above examples suggest, craft micro-businesses found a convenient platform within feminized popular culture. Women make up an estimated $71 \%$ of 'pinners' on Pinterest and 90\% Etsy sellers, and it has long since been argued that television in general, but lifestyle media in particular, is a feminine/feminizing medium (see Jermyn 2006; Levine 2012). Yet despite their prominence within the symbolic environment, it was women's visibility in particular that was (and continues to be) at risk at the level of policy. This lack of representation, as those within the sector have argued, has symbolic implications for the professional identity of homebased craft workers.

This article examines the precise nature of this media visibility at a time of political uncertainty and contends that an investigation into the symbolic meaning of craft cannot overlook the importance of representational culture. Consequently, media studies offers a unique lens through which to examine the politics of craft and contribute meaningful responses to the following questions: how is the meaning of craft articulated in the symbolic environment at a time of political contestation? What is the role of gender in the in the mediated representation of craftwork? These questions inform the analysis of a specific example of representational culture: Kirstie's Crafty Christmas. The follow up to Kirstie's Homemade Christmas (2009) aired in December 2013 on Channel 4 and has been singled out here precisely because it enters the dialogue at a moment of crucial importance when the symbolic meaning of craft is at stake, but it will not be viewed in isolation. The following adopts a cultural approach and examines the paratextual online content and the extratextual material surrounding the show's host who, having enjoyed a prolific media career, has a significant role in shaping public responses to political and social developments.

The one off episode documents Allsopp's attempts to source handmade gifts and decorations from UK craft workers and enables the concerns above to be raised within a very specific context: the Christmas festival. Both craft and festive rituals blur boundaries between work/leisure and public/private in similar ways, which in the case of craft becomes problematic for policy makers. With regard to Kirstie's Crafty Christmas, the use of Christmas as a setting is far from politically innocent and serves as an ideological Trojan horse in which the labour of women is concealed and repackaged as domestic responsibility. Thus, while the programme serves to render (some) craft workers visible, it simultaneously promotes problematic (gendered) hierarchies that refuse to recognise home-based craftwork as legitimate, creative, productive employment. Rather, the work of microentrepreneurs is positioned as non-skilled, domestic unpaid labour.

\section{The Politics of Kirstie's Crafty Christmas}

The fourth instalment of Allsopp's festive programming retreads the thematic and ideological ground covered by Kirstie's Handmade Christmas and Kirstie's Vintage Christmas insofar as it circulates the promise of the 'perfect family Christmas' that can only be accessed via home-based labour. The instructional format and accompanying website (referred to as 'Kirstie's scrapbook') positions the viewer as amateur, who watches/engages in craft activity in the pursuit of domestic bliss. As Allsopp's opening voiceover makes clear, the programme addresses those responsible for reproductive labour during the festive season: 
There's a chill in the air. The twinkly lights are up. The countdown is well underway. But, if you're anything like me, you don't always have weeks to spend making everything from scratch. In this show l'll be meeting some of Britain's best makers who'll share fast, fabulous ideas with me, providing all the ingredients you need to pull off a Christmas to remember.

Thus, in its opening monologue, Kirstie's Crafty Christmas establishes a distinction between the kind of work undertaken by 'Britain's best makers' and that of the viewer and her attempts to 'pull off a Christmas to remember'. Such a distinction has significant implications for our understanding of craft and its relationship to 'ordinary' domestic labour (or perhaps, leisure) and in a series of ways Kirstie's Crafty Christmas redraws the boundary between domestic duties and public work, locating home-based craft practices as part of former. Crucially, Kirstie's Crafty Christmas relies upon the public/private divide as a way of assigning value to the practices that take place within certain spaces.

Allsopp's Devon home is the setting for many of her television series. It was the central focus of Kirstie's Homemade Home, a five part series built around Allsopp's reproductive labour as she transformed the dilapidated six bedroom cottage into the iconic 'Meadowgate'. Meadowgate has subsequently appeared in Kirstie's Handmade Christmas and is the primary location of Kirstie's Crafty Christmas. It is the site of most of the programme's instructional segments during which 'expert' craftspeople from across the UK are invited into Allsopp's home, and more specifically, the feminine spaces within the home (such as the kitchen and dining room) to guide her through a series of craft practices.

To perhaps differentiate itself from a myriad of YouTube lifestyle tutorials, Kirstie's Crafty Christmas employs an overarching narrative to tie each of the instructional segments together. The creation in each of the tutorials is framed as a crucial component of Allsopp's Christmas party (the setting for the climactic final scene). This organizing strategy is of course not uncommon within lifestyle programming, but nevertheless, serves an ideological purpose in the programme insofar as it suggests that the primary purpose of crafting is ultimately to secure the happiness of others and is simply part of women's affective labour during the festive period.

In their article on Christmas and women's domestic work, Sheena J. Vachhani and Alison Pullen (2011) recognize that Christmas is typically perceived to be feminine, with much of its attendant labour undertaken by women. Moreover, they contend that festive rituals 'provide a space for women's domesticity to come to the fore, especially as an organized social activity' (811). The home at Christmas, they argue, complicates the boundaries between public/private and work/home. The home has long since been considered a contested site in which women can experience oppression and/or liberation (see Gillis \& Hollows 2009; Hollows 2006). Equally, 'feminine' handicraft can be read as mundane domestic task or radical political practice. For example, in her canonical book, The Subversive Stitch (1984) Rozsika Parker acknowledges the duality of needlework. She writes: 'The art of embroidery has been the means of educating women into the feminine ideal, and proving that they have attained it, but it also has provided a weapon of resistance to the constraints of femininity' (2010 [1984]: ix). Indeed, in recent years the political 
potential of craft practices has enjoyed unprecedented exposure. Debbie Stoller's Stitch ' $n$ ' Bitch book series and BUST magazines' indie craft shows ('Craftaculars') foreground the resistive potential of DIY culture and form part of a much broader movement in which craft is an intensely political practice. Sometimes referred to as neo-craft, craftivism, micro-revolt or subculture craft, contemporary political craft practices are committed to social justice causes and promote anti-capitalist, environmentalist and feminist ideologies (high profile examples include the 2006 'tank blanket' created by Danish artist, Marianne Jorgensen in protest of the Iraq War and Cat Mazza's 'Radical Lace' show).

As an example of post-recessionary media culture, Kirstie's Crafty Christmas responds (with varying degrees of sensitivity) to the 'create rather than consume' discourses that circulate in craft cultures (see Bain 2016) and thus could be read as an attempt to engage with environmentalist politics. Allsopp repeatedly remarks upon the cost effectiveness of the 'makes' (her handmade tie-die knickers are a thrifty alternative to those which, she maintains, retail for $£ 100$ on the high street), and in her final address to camera, she reminds viewers that the point [of Christmas] is to gather together... it doesn't really matter what you do, just be happy with those you love'. However, both the programme and Allsopp's celebrity persona's relationship to feminist politics is much more complex. Allsopp's controversial comments in the Telegraph (Duggan 2014) regarding young women and motherhood were subject to a great deal of media scrutiny. When discussing the current housing market, Allsopp made the bold claim that young women should prioritize motherhood over higher education: 'I don't have a girl, but if I did l'd be saying 'Darling, do you know what? Don't go to university. Start work straight after school, stay at home, save up your deposit - l'll help you, let's get you into a flat. And then we can find you a nice boyfriend and you can have a baby by the time you're 27"(Allsopp in Duggan 2014). Essentialist comments such as these sit somewhat awkwardly with her position as a self-identifying 'passionate feminist'. Indeed, the controversial comments required Allsopp to make a public declaration of her feminism in a number of media outlets, ${ }^{v}$ beginning with a Good Housekeeping editorial, the title of which reads: 'So what if I'm posh, wear heels and talk about up-cycling on the telly? It doesn't mean I can't be a feminist!'

Allsopp's observation in Good Housekeeping rightly calls into question the simplistic assumption that feminism and domesticity are inherently antithetical and indeed, it is neither possible nor productive to outline the ways in which Allsopp or Kirstie's Crafty Christmas are, or are not, feminist. However, it is worth noting the ways in which Kirstie's Crafty Christmas negotiates its position and adopts certain representational strategies to manage the feminist political potential of DIY culture, because in doing so, it encourages a particular reading of craft and craft practices at a time when its meaning is uncertain, both symbolically and the level of policy. The home, as previously discussed, is a conflicting site of labour and leisure for women, which seemingly intensifies over the festive period. The affective labour associated with Christmas, such as gift giving, feasting and organizing leisure activities, can all be witnessed in Kirstie's Crafty Christmas. While such activities can yield creative satisfaction, their potential for political resistance is carefully managed through the narrative structure of the programme. 
Kirstie's Crafty Christmas is thus part of a broader media discourse that centralizes Christmas, and the kinds of domestic labour the festival demands. However, this visibility alone does not ensure that women's labour is recognized as such or assigned the status of 'masculine' public work. In many ways, despite this visibility, Kirstie's Crafty Christmas doubles its efforts to shore up problematic hierarchies that contribute to the deskilling of the home-based craft worker. This process begins with deskilling Allsopp herself.

\section{Allsopp as Celebrity 'Mumpreneur’?}

Beginning her media career as property expert on Channel 4's Location, Location, Location (2000- ), Allsopp has since become a multiplatform media brand. Following the success of Location, Location, Location, Allsopp co-hosted (with colleague, Phil Spencer) spin off series Relocation, Relocation, and sister series The Property Chain before embarking on solo projects: Kirstie's Homemade Christmas (2009) and Kirstie's Homemade Home (2010). By this time a recognizable household figure, Allsopp appeared on a number of panel shows including Have I Got News for You, Loose Women, and Question Time and made FHM's 2008100 sexiest women list. As an established media presence in 2010, she and Spencer created independent television production company Raise the Roof Productions. It was here that Allsopp's reputation as a craft enthusiast began to develop in outputs such as Kirstie and Phil's Perfect Christmas (2010), Kirstie's Handmade Britain (2011), Kirstie's Handmade Christmas (2011) Kirstie's Vintage Home (2012), Kirstie's Vintage Christmas (2012), Kirstie's Vintage Gems (2013), Kirstie's Handmade Treasures (2013) and Kirstie Allsopp's Home Style (2013). Her celebrity profile extends also beyond the televisual. She is a rumoured advisor to government (Philby 2014), author of five books, designer of several homeware and textile lines (distributed in major UK department stores) and a ubiquitous social media presence on Facebook, Twitter and Instagram.

Throughout her fifteen years of media visibility, she has skilfully cultivated a celebrity persona that continues to resonate with the nation, despite seismic social and economic shifts. Famously described by then Chancellor of the Exchequer, George Osborne as the 'Only Tory on TV', the daughter of Charles Henry Allsopp, $6^{\text {th }}$ Baron Hindlip has carefully managed her privilege and political sympathies in order to achieve the 'ordinariness' demanded of television celebrities, and has done so against the backdrop of recessionary culture. ${ }^{\text {vi }}$ Her ability to negotiate the 'ordinary/extraordinary paradox' (Ellis, 1992) is bolstered by her ability to move seamlessly through those media spaces with a connection to the everyday and the domestic. In so doing, she has become a sort of figurehead for the post-recession 'mumpreneur'.

In her discussion of women, craft and homeworking, Susan Luckman throws a spotlight on the post-Etsy cultural economy and examines the 'downshifting' of women out of the formal (public) workplace back into home-based labour. For Luckman the exponential growth of home-based craft work that coincided with the financial crisis has led to 'new configurations of gender in forms sympathetic to contemporary capitalist and familiar relations and identities' (Luckman 2015: 147). The figure of the 'mumpreneur/mompreneur' befits the new configuration of gender post-recessionary culture demands. The 'mumpreneur' refers to mothers who, 
through the use of new media technologies, are able to sell products out of the home (Duberley and Carrigan, 2012). Though a replacement for the 'yummy mummy' (the postfeminist maternal incarnation of the boom period), her symbolic presence is able to continue the ideological work of her predecessor on account of her class and race privilege in times of austerity. Both figures return to the home (one by 'choice', the other by necessity repackaged as opportunity) and are defined by their relationship to motherhood. The 'mumpreneur' marks a departure from earlier configurations of pre- and post-feminist motherhood insofar as she embarks upon capitalist enterprise within the private sphere. Her identity is both producing and produced within online selling communities, where she renders her reproductive labour visible. vii In their discussion of scrapbooking site Pinterest, Julie Wilson and Emily Chivers Yochin remark upon this peculiar phenomenon in which women's domestic work is 'paradoxically privatized and socialized' (2015: 235).

While Allsopp's visibility and income exceed the 'typical' 'mumpreneur', she borrows from/appropriates the 'humble' aesthetic in ways that encourage an association between the celebrity 'expert' and the home-based worker. Her website, though inactive since 2012, draws heavily on the aesthetics of feminized social media spaces that 'overflow with images of domestic bliss' (Wilson \& Chivers Yochim, 2015: 232). The changing backgrounds double as an advertisement for Elanbach fabrics, a luxury textiles company based in Wales, juxtaposed with the banner's 'make-do-and-mend' imagery: a static photographic image of Allsopp outside her Devon home is overlaid with her logo: a cotton reel and sewing needle against a ribbon with her initials (K.M.A.). The prominence of Allsopp's home is significant as it associates her with the 'mumpreneur'. The 'mumpreneur', as Luckman (n.d) has observed, ostensibly manages the work/life balance through creative homebased work that is made public via online media spaces. Through her extensive media presence, Allsopp performs her commitment to home-work. Meadowgate's prevalence within the official website thus connects Allsopp to the private, the everyday and the familial, while also providing aspirational images of domesticity so commonly associated with the feminine online cultures (Wilson and Chivers Yochim, 2015: 232).

The site's architecture also resembles feminized digital platforms such as Etsy and Big Cartel, insofar as it includes a blogging feature, biographical note and links to Facebook and Twitter pages. Indeed, her 'about me' section employs the confessional and intimate address of many sellers' profiles as she recounts childhood memories and experiences of motherhood. She writes:

I'll admit, the number of boys in my life means I can't get too neat or too precious about our home, which is probably a very good thing, but the best bit about being the only girl in our house is that I don't have to share my bathroom with any of them. I have managed to keep one small corner completely for me.

In her discussion of 'Etsy and eBay mothers', Michele White describes how the architecture of online marketplace spaces encourages the fusing of motherhood and entrepreneurial activity. Stay-at-home mothers have long since been valorised as guardians of morality and family values. Consequently the public display of motherhood shapes sellers' professional identities. Users reproduce conservative 
fantasies of mothering in their online identity work to authenticate their position as 'honest', 'moral' sellers. To use White's terms: 'eBay and Etsy sellers use their selfarticulated gender positions to perform and elide their situation as business owners...Women selling on eBay and Etsy enable their economic and social functioning by linking their position as businesspersons to their more feminine role as stay-at-home mothers.' (2015: 40). Equally, Allsopp's official website successfully entangles these two facets of her celebrity persona as personal blog entries and biographical notes exist alongside links to her latest products. Peddling conservative ideologies of motherhood therefore become an essential part of contemporary self (effacing) promotional strategies. Thus the public visibility of Allsopp's mothering is a crucial facet of not only her celebrity persona, but also her enterprising self.

Allsopp's commitment to motherhood and domesticity is also centralized in print media coverage. Her appearances in Good Housekeeping (June 2012; December 2013; November 2014), Woman and Home (March 2012; September 2015) and Easy Living Magazine (December 2009), ensure motherhood and the affective labour the role inescapably brings are brought to the fore through the use of personal anecdotes about her children and family life. Though they circulate in a different media space, these narratives of motherhood ultimately serve the same purpose as those which appear within the online spaces cultivated by 'mumpreneurs'. They serve to render safe Allsopp's entrepreneurial expertise and preserve conservative gender scripts. In so doing she helpfully embodies the postfeminist promise of 'having it all', managing care work with meaningful creative work.

\section{Deskilling Craft Work in Kirstie's Crafty Christmas}

Despite her off-screen success as homeware and textile designer, Allsopp is positioned as an amateur within the show. viii Indeed, denying her entrepreneurial and creative skill seems to fit as part of the self (effacing) promotion strategy described above, yet it simultaneously renders this labour invisible, which, of course, has implications for how we might view craft skills. Within the context of Kirstie's Crafty Christmas Allsopp's status as professional is overshadowed by her role as 'enthusiast'. She participates in craft work purely for the pleasures it offers, and this pleasure is often coded as infantile. One might argue that the unabashed display of girlish pleasure is in some sense a political act of resistance, however the other representational strategies at work serve to discourage such a reading. The 'girling' of professional women is not uncommon within postfeminist media culture and serves to manage their disruptive potential (see Tasker \& Negra). In the opening scenes, a montage of Allsopp's enthusiastic reactions to her handmade craft recalls imagery of 'fangirling' practices (squealing and stomping her feet in delight) and is interspersed with footage of Allsopp enjoying children's fairground rides, while Julie Andrews' rendition of 'My Favourite Things' provides the soundtrack. The song, which suggests that women's pleasures are tied to the domestic, the ordinary and the everyday, has been co-opted by scrapbooking site Pinterest, the tagline of which reads a few (million) of your favourite things'. Its inclusion in the opening scenes of Kirstie's Crafty Christmas, then, encourages a reading of craft as pleasurable, personal and private. 
On several occasions Allsopp's professional identity is subordinate to her role as 'student', as 'expert' craftspeople demonstrate a series of 'makes', 'makes', which as Allsopp's voiceover is at pains to remind us, are 'simple', 'quick', 'easy'. This hierarchical distinction is important as it serves to create a symbolic divide between the kind of craftsperson Allsopp represents as celebrity 'mumpreneur', and those legitimated as experts within the show. Significantly, there are no apparent microentrepreneurs among Allsopp's guests. Instead, she is joined by food historian, Tasha Marks, renowned neon artist Chris Bracey, textile designer Ellie Jarvis, chef Angela Malik, and props and accessories designer Rosy Nicholas. All but one of the guests to appear on the programme are introduced with a comprehensive biography in which their achievements are made known. For example, Tash Marks is congratulated for her work with the V\&A and her appearance in Vogue magazine; Chris Bracey for his work on the Oxford Street neon light Christmas display and his affiliations with noted film directors Stanley Kubrick and Tim Burton. In all of the cases above, the 'expert's' visibility in the public sphere is remarked upon.

One additional guest, Rebecca Moyster, is not introduced in this way. Moyster is the 'person who has turned the helium balloon in to a fabulous, floaty delight'. She teaches Allsopp how to decorate helium balloon ribbons in the haberdashery section of a department store. Allsopp introduces the segment by encouraging viewers to visit the high street, and large department stores, for inspiration. As her voiceover explains: 'they [the department stores] have teams of people working on their Christmas 365 days of the year and its fantastic the clever tips you can pick up'. Whilst browsing the unnamed department store, she 'meets' Moyster. The viewer could logically assume that Moyster is one of the visual merchandisers Allsopp makes reference to in her voiceover. This assumption is shored up by the location of the segment and the wardrobe (Allsopp's costuming - an outdoor winter coat - marks her as a customer, whereas Moyster appears in professional work attire). However, Moyster is actually the founder of Bonbon Balloons. While precise details of the size and turnover of the company at the time of the episode's broadcast are not readily available, there is evidence to suggest that the venture began as micro-business and was the second of two business ventures (Moysters originally ran a paper goods design company Biba's Tea Party with stores on Etsy and Big Cartel). According to craft and lifestyle magazine, Mollie Makes, Moyster left her full-time job as a senior product developer in 2011 and launched the bespoke luxury balloon company. Branding agency Hustler \& Fox, who according to their mission statement 'like the little guys with the big ideas' and support the 'brands that come from the kitchen table', dedicated one of their \#foxitupfriday 'shout outs' to Moyster, describing her as '\#mumboss' and '\#mumpreneur'. ix

Moyster's 'mumpreneur' status is not at all acknowledged within the programme itself, despite the fact that her race, gender and class status allow her to unproblematically represent the figure. Indeed, certain representational strategies ensure that if any of the guests participate in home-based creative labour it is rendered invisible. The location of Moyster's balloon crafting segment is not politically innocent. The function of the public space, albeit a feminized public space (the department store), associates Moyster with the legitimacy of masculine public work and creates a symbolic divide between public and private spaces and the work that takes place within them. 
The distinction between non-home-based professionals and non-professional home-based workers is made even more explicit in the succeeding segment which is dedicated to viewers' 'makes'. Allsopp's voiceover explains: 'every year I get sent more pictures of things you're making at home for Christmas than you could shake a glittery stick at. I love it. And I want to raise a glass to you all' (my emphasis). Three separate clips of women displaying their makes are subsequently shown in quick succession. The first clip, we are told, features Julia Drew making 'hobbyreindeer' in Scotland. In the second, Jeanne Brooks presents her decoupage plant pots and in the final clip, a group of women, referred to as 'the girls from Liverpool', 'craft over cocktails'. In the second of the three clips, the footage is incredibly low resolution with very poor sound, as if filmed on a mobile phone camera. However, the other two clips have a much higher resolution and on closer inspection appear to be professionally edited, as if they were originally to be included in the main programme. In addition, Julia Drew is wearing a lapel mic and the audio is of a much better quality. Significantly, the footage from the first and third clips has been overlaid with a post-production filter, designed to make footage appear more amateurish. Thus, the segment employs specific representational strategies designed to create an aesthetic distinction between the 'experts' and home-based crafters.

In the programme's exclusive online content available on the Raise the Roof YouTube channel, the full length video clip of Julia Drew making hobbyreindeer can be found, alongside 'How To Make Party Balloons with Rebecca Moyster, Bon Bon Balloons' - notably the only acknowledgement of her company occurs here. Both videos adopt the same aesthetic. Both Drew and Moyster appear in modest workshop spaces: Drew appears in a converted shed, while the slanted roof and skylight suggests that Moyster's workspace is an attic. The editing style in both videos replicates that of the main programme as each clip includes a montage of close-up and panning shots of the final 'makes'. Moreover, there are similarities in sound editing: the audio levels are comparable (Moyster also wears a lapel mic) and each clip is overlaid with incidental music added in postproduction akin to that within the main programme. The aesthetic similarities of these videos are important because they mark both women as micro-entrepreneurs. In the online content both Drew and Moyster are given equal status, but when it comes to the final cut of the broadcast programme, both women's status as micro-entrepreneur (or in the case of Moyster, 'mumpreneur') is denied/symbolically annihilated. Moyster is presented in a public space and therefore afforded the 'legitimacy' of a 'public' identity, whereas Drew is relegated to the position of 'craft enthusiast'. In both cases, the role of micro-entrepreur is significantly devalued, by virtue of its invisibility.

Both Julia Drew (a textile designer and micro-entrepreneur) and the 'girls from Liverpool' appear in the 'crowd scenes' of the final segment, in which Allsopp is seen to throw a party for her expert guests, by way of appreciation. This suggests that those women from the 'amateur' footage section had at one stage been considered for the role of 'expert' in the programme, but for whatever reason did not make the final cut. This editorial decision is significant as it makes a symbolic statement about the nature of craft work. In other words, it strips microentrepreneurs of their legitimacy and privileges a reading of those women as primarily viewers or fans who have submitted their work to Allsopp (as her voiceover implies at the beginning of the 'amateur' footage segment) for validation. 
Allsopp's validation/appreciation comes in the succeeding segment in which 'the simplest little make' is offered as a 'gift back' to her viewers. It is the first of two 'makes' in which Allsopp is unaided and, on both occasions, she stresses her own amateur status. The first 'make' is a glittery bauble. Allsopp claims to have discovered the make in the previous year when she made them for a school Christmas fair. Her introduction into the segment reminds the viewer of the simplicity of the 'little' make, that requires no particular skill set or specialist expensive equipment, and therefore is something she, as an amateur craft enthusiast, is qualified to demonstrate. She affirms/performs her amateur status by likening her tools to household equipment, and by struggling to remember the correct terminology for particular items. She begins her piece to camera by instructing viewers to 'take one polystyrene ball' before stumbling over the remaining directions: 'stick $a$, err...this is a...um... wooden kebab stick type of thing'. The second 'make' appears towards the end of the programme. Here, Allsopp openly acknowledges the absence of an 'expert'. She announces 'Usually at this point in the day we have some nice, good looking boy who comes and teaches me how to make a cocktail, but this year, I'm going it alone'. As with the 'make' above, Allsopp stresses the simplicity of the recipe and informs the audience of tips that she has been 'taught' by experts in the past, in order to remind viewers of her non-expert status. That said, she simultaneously claims authorship over the cocktail, which she names the 'West Country Christmas Apple Cocktail', by offering a personal anecdote that explains its origin, much in the same way as the glitter Christmas baubles which were made for a Christmas school fair. The cocktail came to fruition out of necessity, because she claims it had been 'a brilliant year for apples, and we had so many apples at home that we ended up with bottles and bottles of apple juice'. The cocktail's 'make do and mend' rhetoric appeals to the post-recession return to domestic culture and making one's own produce. In addition to these verbal cues, the mise-en-scène of domesticity - Allsopp appears in the kitchen of Meadowgate, wearing a personalized apron with a polka dot teapot motif, covering her 1950s style emerald green evening dress - discourages a reading of Allsopp as non-homebased professional. The kitsch aesthetic is carefully managed to remain in-keeping with Allsopp's brand, which simultaneously represents and denies the status of the home-based worker.

\section{Conclusion}

The programme's denial of home-based craft workers is important. The symbolic annihilation of the micro-entrepreneur within Kirstie's Crafty Christmas shores up problematic hierarchies, the significance of which can only be understood when contextualized within a historically specific political climate.

The 2013 plans to remove craft from the list of creative industries signalled an attempt to formalize the division between 'creativity' and 'making' that had been growing since the Second World War (see Adamson 2010, Crane 1982, Greenhalgh 1996). Such a shift in policy would have contributed to the forced migration of craft from the public sphere to the private, fostering an association between craft practices and 'non-creative' unpaid domestic labour most commonly undertaken by women. While the 1996 definition of the creative industries was retained, and operationalized in the Creative Industries Economic Estimates 
document, published in January 2015, the methodology for collecting data systematically excluded the contribution of micro-entrepreneurs to the UK economy.

Decisions to classify and categorize various objects, activities and processes in the pursuit of clarity have significant implications which extend beyond policy decisions into the symbolic environment. According to the 2006 Creative and Cultural Skills Footprint:

Of the six sub sectors covered by Creative \& Cultural Skills, craft is the most challenging to define and measure. The nature of the craft industry means it is more a collection of businesses that share a similar approach to an activity than a cohesive industry. For example, two craftsmen working in entirely different disciplines are likely to have more in common than a bespoke carpenter and a large scale furniture manufacturer. ${ }^{x}$

These concerns have long since structured discussions of 'craft' at the level of policy (and beyond). Craft as a term is notoriously difficult to pin down, with economic and technological developments complicating matters further. The Crafts Occupational Standards Board (COSB)'s 1993 Occupational and Functional Mapping report details some of the challenges facing those who seek a clear definition. ${ }^{\mathrm{xi}}$ First, the assumption that craft is synonymous with the term 'handmade' presents a significant problem insofar as any item could be termed craft using such

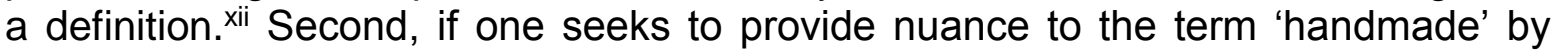
suggesting that the term implies a skill or technique, learned over time, that allows for materials to be manipulated by hand and takes a significant amount of time to master, we raise more questions still; what is an acceptable length of time? How is skill to be defined? Finally, if one is to approach craft from an alternative perspective and assume that 'craft' can best be defined by objects produced, how do we police that boundary? Should objects be functional second to their aesthetic function or vice versa? The very nature of the dilemmas posed in the mapping report suggests an underlying desire to construct craft in somewhat masculine terms: as something that requires a particular level of training and a certain skill set that result in the production of functional objects.

An examination of the representational strategies at work within Kirstie's Crafty Christmas reveal the ways in which the figure of the micro-entrepreneur, whom Allsopp comes to represent, is devalued and deskilled, and craft practices in general, are privatized, trivialized and depoliticized. Moreover, the objects that she produces, we are oft-reminded are 'quick', 'easy' and 'frivolous' as opposed to functional. This symbolic annihilation of feminized craft work enters public consciousness at a time in which the value of the craft industry (particularly that of micro-entrepreneurs) is at stake. Given the importance of media culture in shaping values and understanding, this article has stressed the need to examine the kind of visibility afforded to the craft industry at this time of political uncertainty. The efforts made here to interrogate the mediatisation of craft practices play a crucial role in furthering our understanding of gender inequalities in contemporary culture. 


\section{Acknowledgements}

I would like to thank Tom Phillips and the Feminist Media Studies Research Group at the University of East Anglia for their support and encouragement during the writing of this article.

\section{Bibliography}

Adamson, Glenn (ed) (2010) The Craft Reader, Oxford: Berg

Bain, Jessica (2016) '“Darn right l'm a feminist..Sew what?" The Politics of Contemporary Home Dressmaking: Sewing, Slow Fashion and Feminism', Women's Studies International Forum, 54, 57-66

Bennett, Julia (2013) 'Craft as a creative industry: what doesn't get counted, doesn't count' The Guardian, http://www.theguardian.com/culture-professionalsnetwork/culture-professionals-blog/2013/may/07/crafts-creative-industries-dcms (accessed 30/12/15)

Collins, Liz (2010) 'The Politics of Craft: A Roundtable' in Glenn Adamson (ed) The Craft Reader, Oxford: Berg

Duberley, Joanne and Carrigan, Marylyn (2012) 'The career identities of 'mumpreneurs': Women's experiences of combining enterprise and motherhood', International Small Business Journal, 0:0, pp.1-23

Duggan, Oliver (2014) 'Kirstie Allsopp: Women should put off university to find a nice boyfriend and have babies' The Telegraph, http://www.telegraph.co.uk/culture/tvandradio/10869202/Kirstie-Allsopp-Womenshould-put-off-university-to-find-a-nice-boyfriend-and-have-babies.html (accessed 30/12/15)

Ellis, John (1992) Visible Fictions: Cinema, Television, Video, London: Routledge Gillis, Stacey and Hollows, Joanne (2009) Feminism, Domesticity and Popular Culture, Abingdon: Routledge

Gorman, Juliet (2015) 'The New Domesticity: Homespun Rebellion or Retreat' Etsy https://blog.etsy.com/en/2013/homeward-bound-etsy/ (accessed 30/12/15)

Greenhalgh, Paul (1996) 'History of Craft' in Peter Dormer (ed) The Culture of Craft, Manchester: Manchester University Press

Hollows, Joanne (2006) 'Can I Go Home Yet? Feminism, Post-feminism and Domesticity' in Joanne Hollows and Rachel Moseley (eds) Feminism and Popular Culture, Oxford: Berg

Jermyn, Deborah (2006) 'Bringing out the * in you: SJP, Carrie Bradshaw and the Evolution of Television Stardom' in Sean Redmond and Su Holmes (eds) Framing Celebrity: New Directions in Celebrity Culture, London: Routledge 
Levine, Elana (2012) 'Finding Feminist Media Studies', Antenna, http://blog.commarts.wisc.edu/2012/02/16/finding-feminist-media-studies/ (accessed 31/8/16)

Luckman, Susan (n.d.) 'Gender, Craft and the Creative Economy: Home-bassed Cultural Work and the Etsy Mum, https://www.inter-disciplinary.net/criticalissues/wp-content/uploads/2013/07/luckmanvowpaper.pdf (accessed 30/12/15)

Luckman, Susan (2015) 'Women's Micro-Entrepreneurial Home-working: A 'Magical Solution' to the Work-Life Relationship?', Australian Feminist Studies, 30:84, pp. 146-160

Luckman, Susan (2015) Craft and the Creative Economy, London: Palgrave Macmillan

Parker, Rozsika (2010 [1984]) The Subversive Stitch: Embroidery and the Making of the Feminine, London: I.B. Tauris

Philby, Charlotte (2014) 'Kirstie Allsopp: "They say she is retrograde, backwardthinking" $\mathrm{F}^{* *} \mathrm{k}$ off, I am a feminist!', The Independent http://www.independent.co.uk/news/people/profiles/kirstie-allsopp-they-say-she-isretrograde-backward-thinking-fk-off-i-am-a-feminist-9563205.html (accessed $30 / 12 / 15)$

Polisiczuk, Natasha (2009) 'Christmas with Kirstie', Easy Living, December

Stoller, Debbie (2003) Stitch 'n' Bitch: The Knitter's Handbook, New York: Workman Publishing

Vachhani, Sheena J. and Alison Pullen (2011) Home is where the heart is? Organizing women's work and domesticity at Christmas', Organisation, 18:6, pp. 801-821

White, Michele (2015) Producing Women: The Internet, Traditional Femininity, Queerness, and Creativity, London: Routledge

Wilson, Julie and Chivers Yochin, Emily (2015) 'Pinning Happiness: Affect, Social Media and the Work of Mothers' in Elana Levine (ed) Cupcakes, Pinterest and Ladyporn: Feminized Popular Culture in the Early Twenty-First Century, Chicago: University of Illinois Press

\section{Broadcast Media}

Have I Got News for You (2003- )

Kirstie Allsopp's Home Style (2013).

Kirstie and Phil's Perfect Christmas (2010)

Kirstie's Crafty Christmas (2013)

Kirstie's Handmade Britain (2011) 
Kirstie's Handmade Christmas (2011)

Kirstie's Handmade Treasures (2013)

Kirstie's Handmade Treasures (2013)

Kirstie's Homemade Christmas (2009)

Kirstie's Homemade Home (2010)

Kirstie's Vintage Christmas (2012)

Kirstie's Vintage Gems (2013)

Kirstie's Vintage Home (2012)

Location, Location, Location (2000- )

Loose Women (2011- )

Question Time (2007- )

Relocation, Relocation (2003-2009)

The Great British Bake Off (2010-),

The Great British Sewing Bee (2013- )

The Property Chain (2004-2005)

\section{Print Media}

Good Housekeeping (June 2012; December 2013; November 2014)

Woman and Home (March 2012; September 2015)

\section{Filmography}

The Sound of Music (1965)

\section{Websites}

http://creativeskillset.org/assets/0000/9395/Classifying and measuring the Creati ve Industries.pdf (accessed 30/12/15)

http://kirstieallsopp.co.uk/ (accessed 30/12/15)

http://www.craftscouncil.org.uk/articles/dcms-publish-2015-economic-estimates-forthe-creative-industries/ (accessed 30/12/15)

http://www.craftscouncil.org.uk/content/files/13-06-13-defining and measuring.pdf (accessed 30/12/15) 
http://www.listal.com/list/fhm-100-sexiest-women-world (accessed 30/12/15)

https://www.gov.uk/government/publications/creative-industries-mappingdocuments-1998 (accessed 30/12/15)

https://www.gov.uk/government/publications/creative-industries-mappingdocuments-2001 (accessed 30/12/15)

https://www.gov.uk/government/statistics/creative-industries-economic-estimatesjanuary-2015 (accessed 30/12/15)

\footnotetext{
'The statement initially appeared in early copies of the proposal but was removed at a later date http://creativeskillset.org/assets/0000/9395/Classifying and measuring the Creative Industries.pdf (accessed 30/12/15)

iiii According to the Craft Council's estimates http://www.craftscouncil.org.uk/articles/dcms-publish-2015economic-estimates-for-the-creative-industries/ (accessed 30/12/15)

iii http://www.craftscouncil.org.uk/content/files/Measuring the craft economy-v4.pdf (accessed 31/8/16)

iv Statistics taken from http://www.reuters.com/article/net-us-funding-pinterest-idUSBRE91K01R20130221 \& https://blog.etsy.com/news/2013/etsy-statistics-february-2013-weather-report/ (accessed 30/12/15)

${ }^{v}$ See responses in http://www.stylist.co.uk/people/nature-is-not-a-feminist-kirstie-allsoppdefends-fertility-window-comments-on-newsnight (accessed 31/8/16)

http://www.independent.co.uk/news/people/profiles/kirstie-allsopp-they-say-she-is-retrogradebackward-thinking-fk-off-i-am-a-feminist-9563205.html (accessed 31/8/16)

http://www.telegraph.co.uk/finance/personalfinance/money-saving-tips/10868367/Kirstie-Allsopp-I-dontwant-the-next-generation-of-women-to-suffer-the-same-heartache.html (accessed 31/8/16)
}

\footnotetext{
vi In an interview with Easy Living (2009) magazine, Allsopp claimed that George Osbourne refers to her as the 'the only tory on TV'.

vii According to one of founders of Etsy, Rob Kalin, most online sellers are 'stay-at-home moms....looking to supplement their income rather than make a full-time living' (Kalin in Miller 2007).

viii Of course it is impossible to tell the extent of Allsopp's input, nevertheless, they suggest a level of competency in craft/design.

ix https://hustleandfox.com/what-we-believe/ (accessed 31/8/16)

${ }^{x}$ The statement initially appeared in the 2006 Creative and Cultural Skills Footprint - it has been reproduced here: http://www.craftscouncil.org.uk/content/files/13-06-13-defining and measuring.pdf (accessed 30/12/15)

${ }^{x i}$ Details of the 1993 Occupational and Functional Mapping report can be found here:

http://www.craftscouncil.org.uk/content/files/13-06-13-defining and measuring.pdf (accessed 30/12/15)

xii In addition, if one were to assume handmade implied 'not machine made' then many items typically considered craft would not be included.
} 